УДК 676.15.017.6

\title{
РАЗРАБОТКА ПОЛИКАТИОННОГО ПОЛИМЕРНОГО КЛЕЯ ДЛЯ ПОВЕРХНОСТНОЙ ПРОКЛЕЙКИ БУМАГИ
}

\author{
() О.С. Вдовина", С.Ю. Кожевников \\ ООО «СКИФ Спешиал Кемикалз», Восточная промзона, 7, Дзержинск \\ Нижегородской обл., 606000 (Россия), e-mail: olga_vdovina@skif.ru
}

Статья содержит исследования по разработке поликатионного полимерного клея для поверхностной проклейки бумаги. Рассмотрены вопросы обоснования химического состава полимера исходя из требуемых свойств. Проведен анализ мономеров и определено, что полимер должен быть линейным, получен полимеризацией ряда алкеновых акриловых производных. В макромолекулярной цепы должно содержаться достаточное количество катионных, гидрофильных и гидрофобных функциональных групп и радикалов. Приводится примерная химическая структура звеньев макромолекулярной цепи. Даны характеристики синтезированных полимерных продуктов (клеев) и исследования их гидрофобности.

Ключевые слова: бумага, поверхностная проклейка, гидрофобность, гидрофильность, полимер, сополимер, поликатионный полимер, крахмал, макромолекула, макромолекулярная цепь, производные акриловой кислоты, структурные звенья, краевой угол смачивания.

\section{Введение}

Поверхностная проклейка бумаги (картона) является одним из основных процессов технологии, предназначенных для гидрофобизации бумаги с одновременным повышением ее механической прочности в целом и прочности поверхности, улучшения печатных свойств и экономических показателей производства [1-5]. Неоспоримые достоинства способа поверхностной проклейки предопределили его интенсивное развитие с 60-х гг. XX в. и до настоящих дней. Этому способствовали успехи химии и физики полимеров. На смену животному клею и нативному крахмалу пришли высокоэффективные многочисленные его производные и синтетические полимеры [6, 7], а также новые модели клеильных прессов.

В данной научной работе ставилась цель разработки нового поликатионного полимерного клея для поверхностной проклейки бумаги и картона.

\section{Обоснование химического состава полимерного клея}

Рассматривая клей как систему «вода - полимер», в которой действующим веществом является синтетический полимер, основывались на следующих необходимых свойствах полимера: линейность, низкая вязкость, поликатионность, полигидрофильность, полигидрофобность, полная водорастворимость, адгезионно-когезионная активность. Оптимальное сочетание в полимере широкой гаммы необходимых свойств выполнялось выбором мономеров и отработкой режима синтеза.

Структурные звенья полимера. Теоретический анализ свойств мономеров позволил остановиться на ряде производных метакриловой кислоты, содержащих в молекулах катионные, гидрофильные и гидрофобные группы и радикалы. Являясь производными алкеновых углеводородов, они способны полимеризоваться

Вдовина Ольга Сергеевна - заведующая химической лабораторией, e-mail: olga_vdovina@skif.ru

Кожевников Сергей Юрьевич - кандидат технических наук, доцент, e-mail: skif.special.chemicals@gmail.com (сополимеризоваться) в линейные цепи, длину которых, а, следовательно, среднюю молекулярную массу (MМ) можно легко регулировать при синтезе. В процессе полимеризации мономеров получали сополи-

\footnotetext{
* Автор, с которым следует вести переписку.
} 
меры, построенные из структурных звеньев, представленных на рисунке 1, в различных соотношениях. Основными показателями испытаний сополимеров были: растворимость в воде, вязкость и гидрофобность.

Как видно на рисунке 1, в макромолекулах получаемого продукта содержится большое число гидрофильных и гидрофобных функциональных групп, включая линейную гидрофобную макромолекулярную цепочку углеводородных атомов. Соотношение групп определяет гидрофильно-гидрофобные свойства полимера, а, следовательно, его гидрофобизирующий эффект при нанесении на поверхность бумаги. В лабораторных экспериментах гидрофобность полимера определяли по краевому углу смачивания $(\theta)$.

\section{Задача исследования}

Ставилась задача получить полимер со следующими свойствами: растворимость в воде - полная; динамическая вязкость - в пределах 40-60 сПа; гидрофобность - $\theta$, не менее $70^{\circ}$. Для решения задачи проведен ряд серий поисковых синтезов полимера. При синтезах изменялись: вид мономера, их мольные соотношения и факторы режима синтеза. Каждый синтезированный полимер анализировался на растворимость в воде, вязкость и гидрофобность. Проведенные опыты позволили остановиться на трех продуктах (клеях):

клей $1: \mathrm{C}=22,85, \mu=156,0, \mathrm{G}=1,033, \mathrm{pH}=2,98$

клей 2: $\mathrm{C}=19,25, \mu=44,5, \mathrm{G}=1,022, \mathrm{pH}=3,00$

клей 3: $\mathrm{C}=21,76, \mu=53,0, \mathrm{G}=1,028, \mathrm{pH}=3,07$

где $\mathrm{C}$ - концентрация клея после синтеза, \%; $\mathrm{G}$ - плотность, кг/дм ${ }^{3} ; \mu-$ динамическая вязкость, сПа (1 сПа = $\left.10^{-2} \Pi \mathrm{a} \cdot \mathrm{c}\right)$.

Гидрофобность полимера определяли по высокоточной методике, приведенной в [8]. В данной методике гидрофобность определяется величиной краевого угла смачивания, а угол $\theta$ рассчитывается исходя из геометрических размеров капли на поверхности сухой пленки полимера по формуле $\cos \theta=(\mathrm{d} / 2)^{2}-$ $\mathrm{h}^{2} /(\mathrm{d} / 2)^{2}+\mathrm{h}^{2}$. Данные для расчета иллюстрируются рисунком 2 .

\section{Результаты исследований}

Синтезированный клей разбавляли водой в 10, 100 и 1000 раз; по 1 мл каждого раствора наносили на стекло, высушивали и оценивали гидрофобность полученных пленок по растеканию капли воды; каплю воды фотографировали, по снимку определяли диаметр и высоту капли. Расчетные данные гидрофобности пленок клея приведены в таблице.<smiles>CCCC(C)C(=O)O</smiles>

I<smiles>CCCC(C)C(=O)OCC</smiles>

IV<smiles>CCC(C)C(=O)OC</smiles>

II<smiles>CCOC(=O)C(C)CC</smiles>

III

Рис. 1. Структурные звенья макромолекул сополимера: I - акриловой кислоты; II - метилметакрилата; III - циклогексилметакрилата; IV - стеарилметакрилата; V - диметиламиноэтилметакрилата

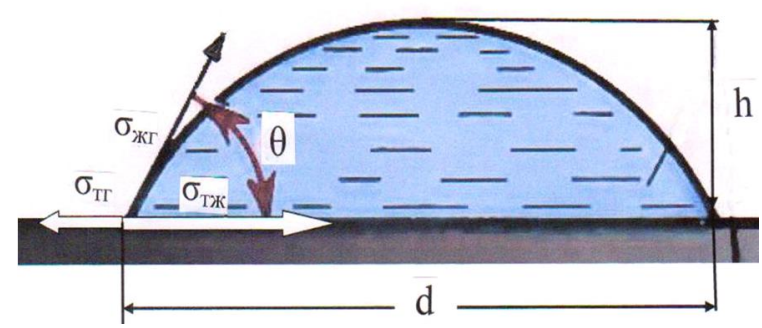

Рис. 2. Капля воды на поверхности пленки полимера: $\theta$ - краевой угол смачивания, град.; $\mathrm{d}$ - диаметр капли, мм; h - высота капли, мм 
Лабораторные данные для расчета и расчетные значения краевого угла смачивания для клеев

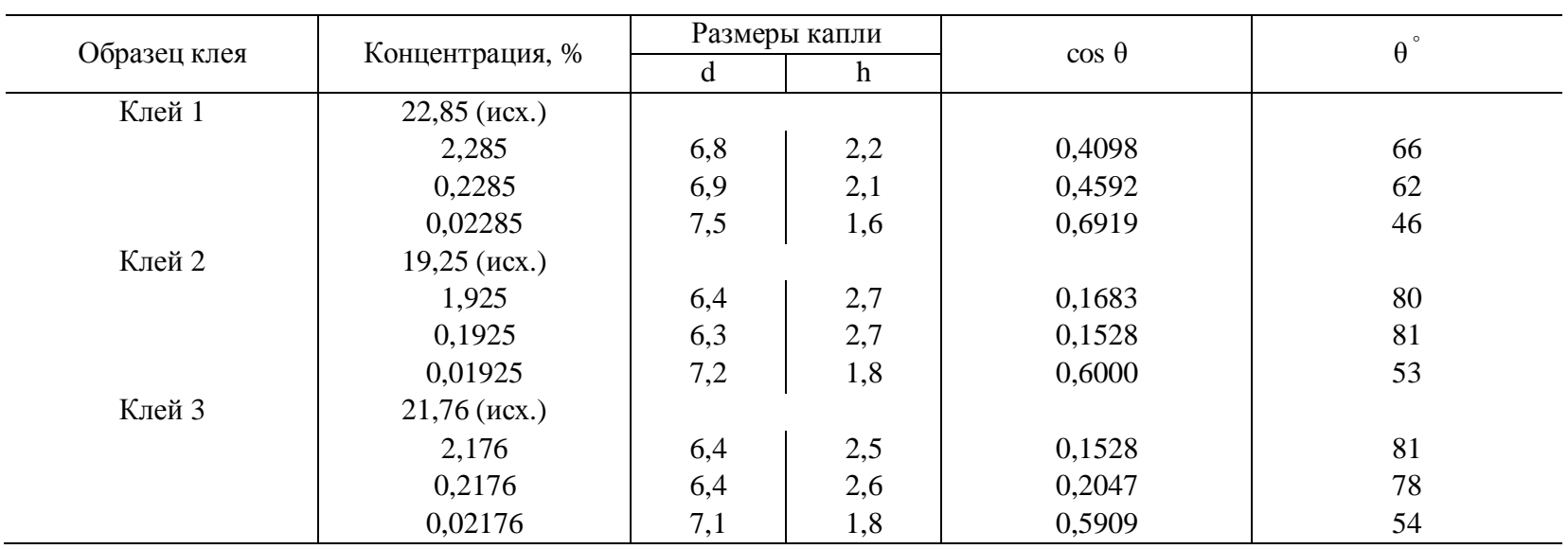

Сравнивая гидрофобность 3-х исследованных образцов клея по краевому углу смачивания $\theta$, выявляли, что клей 2 и клей 3 имеют большую гидрофобность $(\theta$ в пределах 78-81), чем клей 1 ( $\theta$ в пределах $\left.62-66^{\circ}\right)$. Клеи 2 и 3 удовлетворяют заданному условию гидрофобности $-\theta$, не менее $70^{\circ}$. Важно отметить наличие предела гидрофобности для исследуемых образцов клея. Так, для клея 1 - это 62-66 ${ }^{\circ}$, а для клеев 2

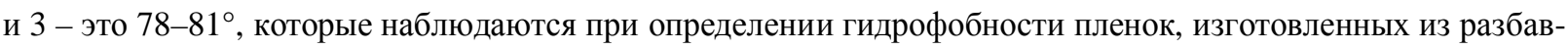
ленных растворов в 10 и 100 раз. Гидрофобность пленок из разбавленных растворов в 1000 раз заметно ниже - на 26-28 (для клеев 2 и 3), для клея 1 примерно на 20․ Такой характер зависимости гидрофобности пленок от концентрации клея позволяет целенаправленно управлять гидрофобностью поверхности бумаги в пределах значений $\theta$ от 0 до 80, т.е. от предельной смачиваемости бумаги до высокой гидрофобности. Как обладающие более высокими гидрофобизирующими свойствами, клеи 2 и 3 были выбраны для дальнейших исследований в процессе поверхностной проклейки бумаги и картона.

Линейность и молекулярная масса (МM) макромолекул являются основными факторами вязкости и растворимости. Литературные источники рекомендуют для поверхностной обработки использовать полимеры невысокой ММ (средняя ММ в пределах 30000-60000 г/моль) [9]. Укажем, что при полимеризации образуется смесь макромолекул различной длины, т.е. всегда имеет место макромолекулярная полидисперсность (смесь фракций макромолекул различной длины). Распределение фракций по длине макромолекул имеет существенное значение для целей поверхностной проклейки бумаги.

Свое действие на поверхность бумаги полимер оказывает после его распределения и закрепления. А эти два процесса связаны адсорбцией полимера на поверхности бумаги. Общая закономерность следующая: чем больше молекулярная масса полимера, тем сильнее он адсорбируется. Таким образом, при адсорбции полидисперсного полимера в первую очередь адсорбируются высокомолекулярные фракции, оттесняя низкомолекулярные фракции от поверхности. Следовательно, если на поверхности бумаги адсорбируется полимолекулярный слой полимера, то преимущественное распределение фракций будет по убывающим от поверхности ММ.

Поликатионность полимеру придается, как видно на рисунке 1, структурным звеном диметиламиноэтилметакрилата. Регулируя его содержание в макромолекулярной цепи молярным соотношением его с другими мономерами на стадии синтеза, катионную плотность сополимера можно менять в широких пределах. Катионная плотность оказывает влияние на закрепление полимера на поверхности бумаги, а также создает условия для образования более плотной структуры поверхностного гидрофобного слоя. Этот эффект определяется электростатическим притяжением катионактивного полимера и анионактивного волокна поверхности бумаги.

\section{Выводы}

1. Обоснован выбор мономеров для получения клея, предназначенного для поверхностной проклейки бумаги. Это ряд производных метакриловой кислоты, содержащих в молекулах катионные, гидрофильные и гидрофобные группы и радикалы.

2. В результате поисковых экспериментов по синтезу полимеров с заданными свойствами получены 3 образца полимерного клея для поверхностной проклейки бумаги, различающиеся соотношением вида и количества мономеров и режимами синтеза.

3. Для 3-х образцов полимерного клея исследована гидрофобность. По величине краевого угла смачивания $\theta$ выбраны клеи 2 и 3 как обладающие высокой гидрофобностью - до 80, для продолжения исследований по гидрофобизации бумаги. 


\section{Список литературы}

1. Крылатов Ю.А., Ковернинский И.Н. Проклейка бумаги. М., 1987. 288 с.

2. Иванов С.Н. Технология бумаги. М., 2006. 696 с.

3. Фляте Д.М. Технология бумаги. М., 1988. 440 с.

4. Горжанов В.В., Темрук В.И., Соловьева Т.В. Влияние композиционного состава бумаги на ее поверхностную проклейку в клеильном прессе бумагоделательной машины // Энерго- и материалосберегающие экологически чистые технологии : тезисы докладов VII Междунар. науч.-техн. конф. Гродно, 2007. С. 141.

5. Соловьева Т.В. Экономия проклеивающих материалов в производстве бумаги для офисной техники // Энергои материалосберегающие экологически чистые технологии : материалы VI Междунар. науч.-техн. конф. Гродно, 2006. Ч. 2. С. 283-285.

6. Петров А.П. Поверхностная проклейка бумаги и картона. М., 1968. 80 с.

7. Копыльцов А.А. Применение крахмала в производстве бумаги и картона. М., 2008. 52 с.

8. Лабораторные работы и задачи по коллоидной химии / под ред. Ю.Г. Фролова и А.С. Гродского. М., 1986. 216 с.

9. Patent 2009/0068485 (US). Cationic surface sizingagent and newsprint paper / K. Inaoka, T. Nakata, Y. Hashiguchi. 2009. $12 \mathrm{~s}$.

Поступило в редакцию 18 декабря 2014 г.

После переработки 14 января 2015 г.

\section{ING PAPER}

Vdovina O.S. , Kozhevnikov S.Iu. DEVELOPMENT OF POLYMER POLYCATIONIC ADHESIVE SURFACE SIZ-

Co.Ltd «SKIF Special Chemical», Vostochnaya promzona, 7, Dzerzhinsk, Nizhny Novgorod region, 606000 (Russia),

e-mail: olga_vdovina@skif.ru

The article contains a study on the development of a polycationic polymer adhesive surface sizing of paper. The problems study the chemical composition of the polymer, based on the properties required. The analysis of the monomers and defined-Leno that the polymer should be linear, and received a number of alkene polymerization of acrylic derivatives. The macromolecular flails must contain sufficient cationic, hydrophilic and hydrophobic functional groups and radicals. A tentative chemical structure of macromolecular chain links. The characteristics of the synthesized polymer products (adhesives) and the study of their hydrophobicity.

Keywords: paper, surface sizing, hydrophobicity, hydrophilicity, a polymer, a copolymer, a polycationic polymer, starch macromolecule, macromolecular chain derived from acrylic acid structural units, the contact angle.

\section{References}

1. Krylatov Iu.A., Koverninskii I.N. Prokleika bumagi. [Paper sizing]. Moscow, 1987, 288 p. (in Russ.).

2. Ivanov S.N. Tekhnologiia bumagi. [Technology papers]. Moscow, 2006, 696 p. (in Russ.).

3. Fliate D.M. Tekhnologiia bumagi. [Technology papers]. Moscow, 1988, 440 p. (in Russ.).

4. Gorzhanov V.V., Temruk V.I., Solov'eva T.V. Energo- i materialosberegaiushchie ekologicheski chistye tekhnologii: tezisy dokladov VII mezhdunar. nauch.-tekhn. konf. [Energy and material-clean technology: abstracts of the VII International Scientific and Technical Conference]. Grodno, 2007, p. 141. (in Russ.).

5. Solov'eva T.V. Energo- i materialosberegaiushchie ekologicheski chistye tekhnologii: tezisy dokladov VI mezhdunar. nauch.-tekhn. konf. [Energy and material-clean technology: abstracts of the VI International Scientific and Technical Conference]. Grodno, 2006, part 2, pp. 283-285. (in Russ.).

6. Petrov A.P. Poverkhnostnaia prokleika bumagi i kartona. [Surface sizing of paper and paperboard]. Moscow, 1968, 80 p. (in Russ.).

7. Kopyl'tsov A.A. Primenenie krakhmala v proizvodstve bumagi i kartona. [The use of starch in the manufacture of paper and paperboard]. Moscow, 2008, 52 p. (in Russ.).

8. Laboratornye raboty $i$ zadachi po kolloidnoi khimii. [Laboratory work and objectives of colloid chemistry]. Ed. Iu.G. Frolov, A.S. Grodskii. Moscow, 1986, 216 p. (in Russ.).

9. Patent 2009/0068485 (US). 2009.

\footnotetext{
* Corresponding author.
} 